D) Check for updates

Cite this: Food Funct., 2017, 8, 2022

\title{
Leaf parts from Greek artichoke genotypes as a good source of bioactive compounds and antioxidants
}

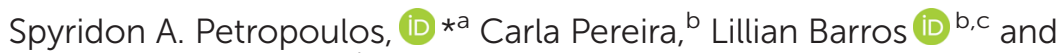 \\ Isabel C. F. R. Ferreira*b
}

\begin{abstract}
Globe artichoke is an important vegetable in the Mediterranean diet. However, the marketable part of the plant constitutes a small portion of its total crop biomass and large amounts of waste are produced during its cultivation. In this study, the phenolic compound content and composition and the antioxidant activity of leaf parts [blades (SLB), petioles and midribs (SPM)] from various Greek artichoke genotypes were evaluated. The results showed significant variation in antioxidant activities and bioactive compound contents between the studied genotypes, with the leaf blades of most of the genotypes having a high content of flavonoids (mainly luteolin glycoside derivatives), which ranged between 49 and $78 \%$ of total phenolic compounds (TPC). In contrast, in petioles and midribs phenolic acids (mainly hydroxycinnamic acid derivatives) were the main phenolic compounds, ranging between 64 and $76 \%$ of TPC. The antioxidant activity of blades was significantly higher than that of petiole and midribs for all the genotypes and the tested assays. In conclusion, artichoke leaves (blades, petioles and midribs) of the studied genotypes showed different bioactive compound profiles and significant antioxidant properties, and could be further used in the food and nutraceuticals industries as a cheap source of phenolic compounds and antioxidants.
\end{abstract}

Received 4th March 2017 Accepted 19th April 2017

DOI: $10.1039 / \mathrm{c} 7$ fo00356k

rsc.li/food-function of artichoke present significant antioxidant activity, ${ }^{6-8}$ and for this purpose they are the main ingredients in many dietary supplements and drugs. In particular, leaves are the most common plant part used for therapeutic purposes, since they have numerous medicinal properties including antitumor, antioxidant, antibacterial, antifungal, and hepatoprotective effects and so forth, mostly attributed to their high content of phenolic compounds. ${ }^{7,9,10}$ Moreover, leaf extracts, infusions and decoctions have shown significant scavenging properties against reactive oxygen species. ${ }^{11}$

The phenolic compound content and composition of artichoke is affected by the genotype and the plant part (edible and non-edible parts), as well as by the growth conditions, cultivation practices and harvest stage. ${ }^{12-16}$ In particular, according to Lombardo et al. ${ }^{17}$ total phenolic content and phenolic compound composition differed significantly among seventeen Italian globe artichoke cultivars, while they also observed significant differences among the studied plant parts (receptacle, floral stem, inner and outer bracts). The main phenolic compounds reported for artichoke heads so far include mainly caffeoylquinic acids, such as chlorogenic acid, 1,5-dicaffeoylquinic acid and cynarin, ${ }^{11,18}$ as well as apigenin and luteolin derivatives, such as apigenin-7-O-glucuronide ${ }^{19-22}$ and flavone glycosides. ${ }^{3,23,24}$

\footnotetext{
${ }^{a}$ Laboratory of Vegetable Production, University of Thessaly, Fytokou Street, 38446 N. Ionia, Magnissia, Greece. E-mail: fangio57gr@gmail.com; Fax: +30-2421093155; Tel: $+30-2421093196$

${ }^{b}$ Mountain Research Centre (CIMO), ESA, Polytechnic Institute of Bragança, Campus de Santa Apolónia, 1172, 5300-253 Bragança, Portugal. E-mail: iferreira@ipb.pt; Fax: +351-273325405; Tel: +351-273303219

${ }^{c}$ Laboratory of Separation and Reaction Engineering (LSRE), Associate Laboratory LSRE/LCM, Polytechnic Institute of Bragança, Campus de Santa Apolónia, 1134,

5301-857 Bragança, Portugal
} 
Bearing in mind the great genetic diversity in artichoke germplasm throughout the Mediterranean, the aim of the present study was to evaluate the antioxidant activity of leaf parts (blades and midribs) of various artichoke landraces and cultivars that are mainly cultivated in Greece. Moreover, although the phenolic compound composition of artichoke byproducts and plant parts has been reported, to the best of our knowledge no studies regarding the individual leaf parts have been reported so far. Considering the portion of total biomass that artichoke leaves constitute and their large size, knowing the chemical composition of different leaf parts (blades, midribs and petioles) is of special interest. Therefore, the phenolic compound composition of individual leaf parts was also evaluated in order to provide information regarding their phenolics profile and evaluate the possibility of using specific by-products as alternative sources of phenolic compounds in the food and pharmaceutical industries.

\section{Materials and methods}

\section{Plant materials and sampling}

Field experiments were carried out at the experimental farm of the University of Thessaly in Velestino. Samples of four globe artichoke [Cynara cardunculus L. ssp. scolymus (L.) Fiori] and two wild artichoke [Cynara cardunculus L. subsp. sylvestris (L.) Fiori] genotypes were assessed for their phenolic compound composition and antioxidant activity.

The studied genotypes have been previously described by the authors. ${ }^{25}$ More specifically, the following genotypes were evaluated: (a) local landrace with dark purple round heads (S1), (b) Greek cultivar "Purple of Attika" with purple round heads (S2), (c) wild globe artichoke with green small flat round heads and bracts with small spines (S3), (d) commercial cultivar with green round heads (Geniki Fytotechniki S.A.; S4), (e) commercial cultivar with dark purple oblong heads and bracts with small spines (Geniki Fytotechniki S.A.; S5), and (f) wild globe artichoke with green small round heads and bracts with big spines (S6).

Samples of leaves were collected prior to anthesis from the latest fully developed leaves, and further separated into blades (SLB) and petioles and midribs (SPM). All samples were taken from plants at the third year after crop establishment, the growth stage when artichoke plants are considered to have reached their full production potential. After leaf separation, all samples were chopped, placed in air sealed bags and under deep freezing conditions $\left(-80{ }^{\circ} \mathrm{C}\right)$, and lyophilized prior to further analyses.

\section{Phenolic compound characterization}

For phenolic compound analyses, extracts were prepared by stirring the dry sample $(1 \mathrm{~g})$ and $30 \mathrm{~mL}$ of methanol/water $\left(80: 20 \mathrm{v} / \mathrm{v}\right.$, at $25{ }^{\circ} \mathrm{C}$ at $\left.150 \mathrm{rpm}\right)$ for $1 \mathrm{~h}$ and afterwards filtered using Whatman paper no. 4 . The residue was then extracted with an additional portion of methanol/water and the combined extracts were evaporated under reduced pressure (Büchi R-210 rotary evaporator; Flawil, Switzerland) until the complete removal of methanol. The aqueous phase was frozen and lyophilized (FeeeZone 4.5, Labconco, Kansas City, MO, USA).

The hydroalcoholic extracts were re-dissolved in methanol/ water $(80: 20 \mathrm{v} / \mathrm{v})$ to a final concentration of $2 \mathrm{mg} \mathrm{mL}^{-1}$ for phenolic compound identification and quantification. LC-DAD-ESI/MSn analyses were performed for phenolic compound identification and quantification, using a Dionex Ultimate 3000 UPLC instrument (Thermo Scientific, San Jose, CA, USA) equipped with a diode-array detector and coupled to a mass detector, using a procedure previously reported by Bessada et $a .^{26}$ The chromatogram was recorded at several wavelengths, characteristic of different classes of polyphenols, such as $280 \mathrm{~nm}$ for hydroxybenzoic acids and flavonones, $330 \mathrm{~nm}$ for hydroxycinnamic acids, and $370 \mathrm{~nm}$ for flavones. For quantitative analysis, a calibration curve for each available phenolic standard was constructed based on the UV signal. For the identified phenolic compounds for which a commercial standard was not available, quantification was performed through the calibration curve of the most similar available standard. The results were expressed as mg per $\mathrm{g}$ of extract.

\section{Antioxidant activity}

Antioxidant activity was evaluated with four different assays (DPPH radical-scavenging activity, reducing power, inhibition of $\beta$-carotene bleaching in the presence of linoleic acid radicals and inhibition of lipid peroxidation using TBARS in brain homogenates) as has been previously described by the authors. ${ }^{27}$

The same extracts from the phenolic characterization were re-dissolved in methanol/water $(80: 20, \mathrm{v} / \mathrm{v})$ in order to be subjected to distinct in vitro antioxidant activity assays, at a final concentration of $20 \mathrm{mg} \mathrm{mL} \mathrm{m}^{-1}$ and further diluted to different concentrations.

DPPH radical-scavenging activity was evaluated using an ELX800 microplate reader (Bio-Tek Instruments, Inc.; Winooski, VT, USA), and calculated as a percentage of DPPH discoloration using the formula: $\left[\left(A_{\mathrm{DPPH}}-A_{\mathrm{S}}\right) / A_{\mathrm{DPPH}}\right] \times 100$, where $A_{\mathrm{S}}$ is the absorbance of the solution containing the sample at $515 \mathrm{~nm}$, and $A_{\mathrm{DPPH}}$ is the absorbance of the DPPH solution. Reducing power was evaluated by the capacity to convert $\mathrm{Fe}^{3+}$ to $\mathrm{Fe}^{2+}$, measuring the absorbance at $690 \mathrm{~nm}$ in the microplate reader mentioned above. Inhibition of $\beta$-carotene bleaching was evaluated through the $\beta$-carotene/ linoleate assay; the neutralization of linoleate free radicals avoids $\beta$-carotene bleaching, which was measured using the formula: ( $\beta$-carotene absorbance after $2 \mathrm{~h}$ of assay/initial absorbance) $\times 100$. Lipid peroxidation inhibition in porcine brain homogenates was evaluated by the decrease in thiobarbituric acid reactive substances (TBARS); the colour intensity of malondialdehyde-thiobarbituric acid (MDA-TBA) was measured by its absorbance at $532 \mathrm{~nm}$; the inhibition ratio (\%) was calculated using the following formula: $[(A-B) / A] \times 100 \%$, where $A$ and $B$ are the absorbances of the control and the sample solution, respectively. ${ }^{27}$ The results were expressed as $\mathbf{E C}_{50}$ values (the sample concentration providing $50 \%$ antioxidant 
activity or 0.5 absorbance in the reducing power assay) for antioxidant activity, and Trolox was used as a positive control.

\section{Statistical analysis}

For chemical composition analyses and antioxidant activity assays, three samples were analyzed for each treatment, whereas all the assays were carried out in triplicate. The results were expressed as the mean values and standard deviations (SD), and analyzed using one-way analysis of variance (ANOVA) followed by Tukey's HSD test with $p=0.05$. This analysis was carried out using the SPSS v. 23.0 program (IBM Corp., Armonk, NY, USA).

\section{Results and discussion}

The phenolic compound profile of hydromethanolic extracts of globe artichoke leaf blades is presented in Table 1. The samples of the studied genotypes were characterized by the presence of eleven phenolic compounds, from which six were classified as phenolic acids and five as flavonoid glycoside derivatives (Table 1). The phenolic acids were all identified as hydroxycinnamoyl derivatives (compounds with peak numbers 1-5 and 10), being distinguished and identified by the typical fragmentation patterns as described by Clifford et al., ${ }^{28,29}$ with the exception of compounds with peak numbers 2 and 3 that were identified as caffeic acid hexoside $\left([\mathrm{M}-\mathrm{H}]^{-}\right.$at $\left.\mathrm{m} / \mathrm{z} 341\right)$ and $p$-coumaric acid hexoside $\left([\mathrm{M}-\mathrm{H}]^{-}\right.$at $m / z$ 325). All data for acylquinic acids in this study used the recommended IUPAC numbering system. ${ }^{30}$ The identified flavonoids were all flavones (compounds with peak numbers 6-9 and 11), being all luteolin glycoside derivatives ( $\lambda_{\max }$ around $348 \mathrm{~nm}$ and an $\mathrm{MS}^{2}$ fragment at $\left.\mathrm{m} / \mathrm{z} 285\right)$. Compounds with peak numbers 1-10 have been previously reported in artichoke leaves, ${ }^{31}$ leaf extracts, ${ }^{11}$ by-products, ${ }^{32,33}$ dietary supplements, ${ }^{34}$ cultivated artichoke, Madeira cardoon and artichoke-based dietary supplements (juices and dragées). ${ }^{25,35}$ Compound with peak number 11 presented a pseudomolecular ion $[\mathrm{M}-\mathrm{H}]^{-}$at $\mathrm{m} / \mathrm{z}$ 533, releasing $\mathrm{MS}^{2}$ fragments at $m / z 285\left([\mathrm{M}-\mathrm{H}-86-162]^{-}\right.$, loss of a malonylhexoside moiety). A compound with a similar pseudomolecular ion has been identified by Gouveia and Castilho $^{35}$ in artichoke-based dietary supplements (dragées) as a luteolin-O-diacetylhexoside. However, the fragmentation pattern presented matched better with luteolin-O-malonylhexoside, also identified by Pandino et al. ${ }^{36}$ in leaves of globe artichoke. Therefore, this compound was tentatively assigned as luteolin-7-O-malonylglucoside.

Flavonoids were the most abundant phenolic compounds in leaf blades for most of the studied genotypes $(57-78 \%$ of total phenolic compounds, TPC), except for genotype SLB4 where phenolic acids prevailed (75.8\% of TPC) and genotype SLB6 where equal amounts of total flavonoids (TF) and total phenolic acids (TPA) were detected (48.9 and 51.1\%, respectively) (Table 2). Flavonoid content ranged from 6.9 (genotype SLB6) to $25.9 \mathrm{mg}$ per $\mathrm{g}$ of extract (genotype SLB5). Phenolic compound composition varied between the studied genotypes, with 5-O-caffeoylquinic acid and luteolin-7-O-rutinoside being among the most abundant phenolics in genotype SLB4, and luteolin-7-O-glucoside, pinoresinol-4-O-hexoside, 3,5-Odicaffeoylquinic acid and luteolin-7-O-malonylglucoside in genotype SLB5.

The phenolic compound profile of hydromethanolic extracts of globe artichoke leaf petioles and midribs is presented in Table 3. Samples of the studied genotypes were characterized by the presence of thirteen phenolic compounds, of which nine were classified as phenolic acids (compounds with peak numbers 1-4, 7 and 9-12) and four as flavonoid glycoside derivatives (compounds with peak numbers 5, 6, 8 and 13) (Table 3). Compounds with peak numbers 2-8, 10, 11 and 13 have been previously reported in the literature in different artichoke samples. ${ }^{3,5,11,33,35,36}$ Compounds with peak numbers 1 and 9 were identified as the cis form of hydroxycinnamoyl derivatives, since these would be expected to elute before the corresponding trans ones, as observed after UV irradiation (366 nm, $24 \mathrm{~h}$ ), of hydroxycinnamic acids in our laboratory. ${ }^{37}$ cis and trans isomers of 3-O-caffeoylquinic acid (compounds with peak numbers 1 and 2) and 3,5-O-dicaffeoylquinic acid (compound with peak numbers 9 and 10), as all the hydroxycinnamoyl derivatives identified, were distinguished and identified by typical fragmentation patterns as described by

Table 1 Retention time $\left(R_{\mathrm{t}}\right)$, wavelengths of maximum absorption in the visible region $\left(\lambda_{\text {max }}\right)$, mass spectral data and tentative identification of phenolic compounds in globe artichoke leaf blades

\begin{tabular}{llllll}
\hline Peak & $\begin{array}{l}R_{\mathrm{t}} \\
(\mathrm{min})\end{array}$ & $\begin{array}{l}\lambda_{\max } \\
(\mathrm{nm})\end{array}$ & $\begin{array}{l}\text { Molecular ion } \\
{[\mathrm{M}-\mathrm{H}]^{-}(\mathrm{m} / \mathrm{z})}\end{array}$ & Main $\mathrm{MS}^{2}$ fragments $(\mathrm{m} / \mathrm{z})$ & Tentative identification \\
\hline 1 & 4.59 & 324 & 353 & $191(100), 179(46), 173(3), 161(5), 135(6)$ & 3-O-Caffeoylquinic acid \\
2 & 6.14 & 326 & 341 & $179(100)$ & $\begin{array}{l}\text { Caffeic acid hexoside } \\
p \text {-Coumaric acid hexoside }\end{array}$ \\
3 & 6.83 & 310 & 325 & $163(100)$ & 5 - $O$-Caffeoylquinic acid \\
4 & 7.46 & 326 & 353 & $191(100), 179(10), 161(3), 135(3)$ & 5 - $O$-Feruloylquinic acid \\
5 & 14.03 & 325 & 367 & $193(12), 191(100), 173(6), 143(3), 134(5)$ & Luteolin-7- $O$-rutinoside \\
6 & 18.57 & 348 & 593 & $285(100)$ & Luteolin-7-O-glucuronide \\
7 & 18.90 & 346 & 461 & $285(100)$ & Luteolin-7-O-glucoside \\
8 & 19.54 & 347 & 447 & $285(100)$ & Pinoresinol-4- $O$-hexoside \\
9 & 20.11 & 227,279 & 519 & $357(100), 343(9), 151(50), 136(4)$ & $3,5-O$-Dicaffeoylquinic acid \\
10 & 21.15 & 328 & 515 & $353(94), 335(5), 191(100), 179(12), 173(3), 161(3), 135(3)$ & Luteolin-7- $O$-malonylglucoside \\
11 & 24.42 & 347 & 533 & $489(100), 285(50)$ &
\end{tabular}


Table 2 Phenolic compound quantification in leaf blades (mg per $\mathrm{g}$ of extract) of the studied globe artichoke genotypes

\begin{tabular}{|c|c|c|c|c|c|c|}
\hline \multirow[b]{2}{*}{ Peaks } & \multicolumn{6}{|l|}{ Genotypes } \\
\hline & SLB1 & SLB2 & SLB3 & SLB4 & SLB5 & SLB6 \\
\hline $1^{\mathrm{I} a}$ & $0.68 \pm 0.02 c$ & $0.61 \pm 0.04 \mathrm{c}$ & $0.46 \pm 0.01 d$ & $1.50 \pm 0.02 b$ & $1.70 \pm 0.06 a$ & $0.69 \pm 0.01 c$ \\
\hline $2^{\mathrm{I}}$ & $0.46 \pm 0.03 \mathrm{de}$ & $0.42 \pm 0.02 \mathrm{e}$ & $0.49 \pm 0.01 \mathrm{~cd}$ & $0.470 \pm 0.002 \mathrm{~cd}$ & $0.628 \pm 0.005 b$ & $1.00 \pm 0.01 \mathrm{a}$ \\
\hline $3^{I I}$ & $0.39 \pm 0.03 c$ & $0.37 \pm 0.01 c$ & $0.28 \pm 0.02 d$ & $0.38 \pm 0.01 \mathrm{c}$ & $0.52 \pm 0.01 \mathrm{~b}$ & $1.04 \pm 0.03 a$ \\
\hline $4^{\mathrm{I}}$ & $2.46 \pm 0.01 c$ & $1.4 \pm 0.1 \mathrm{~d}$ & $0.94 \pm 0.03 d$ & $51.1 \pm 0.8 \mathrm{a}$ & $10.6 \pm 0.4 b$ & $2.79 \pm 0.08 c$ \\
\hline $5^{\text {III }}$ & $0.286 \pm 0.001 \mathrm{~b}$ & $0.18 \pm 0.05 c$ & $0.118 \pm 0.009 d$ & $0.56 \pm 0.02 \mathrm{a}$ & $0.518 \pm 0.002 \mathrm{a}$ & $0.120 \pm 0.001 \mathrm{~d}$ \\
\hline $6^{\mathrm{IV}}$ & $2.33 \pm 0.06 c$ & $2.2 \pm 0.1 \mathrm{c}$ & $3.4 \pm 0.2 \mathrm{~b}$ & $7.8 \pm 0.1 \mathrm{a}$ & $1.31 \pm 0.07 \mathrm{~d}$ & $\mathrm{tr}$ \\
\hline $7^{\mathrm{IV}}$ & $4.22 \pm 0.04 a$ & $2.07 \pm 0.08 b$ & $1.9 \pm 0.1 b$ & nd & nd & nd \\
\hline $8^{\mathrm{IV}}$ & $1.52 \pm 0.02 \mathrm{e}$ & $3.4 \pm 0.1 b c$ & $2.58 \pm 0.07 d$ & $3.5 \pm 0.3 \mathrm{~b}$ & $8.5 \pm 0.2 \mathrm{a}$ & $3.05 \pm 0.3 c$ \\
\hline $9^{\mathrm{IV}}$ & $2.63 \pm 0.05 d$ & $2.92 \pm 0.08 c$ & $1.93 \pm 0.03 \mathrm{e}$ & $3.57 \pm 0.09 b$ & $4.4 \pm 0.2 \mathrm{a}$ & $2.1 \pm 0.1 \mathrm{e}$ \\
\hline $10^{\mathrm{I}}$ & $0.95 \pm 0.03 \mathrm{~d}$ & $0.50 \pm 0.03 \mathrm{f}$ & $0.74 \pm 0.05 \mathrm{e}$ & $2.86 \pm 0.05 b$ & $5.45 \pm 0.07 \mathrm{a}$ & $1.6 \pm 0.1 \mathrm{c}$ \\
\hline $11^{\mathrm{IV}}$ & $1.04 \pm 0.05 \mathrm{~d}$ & $1.60 \pm 0.08 \mathrm{c}$ & $0.52 \pm 0.04 \mathrm{e}$ & $3.21 \pm 0.3 \mathrm{~b}$ & $11.8 \pm 0.4 \mathrm{a}$ & $1.75 \pm 0.07 \mathrm{c}$ \\
\hline TPA & $5.23 \pm 0.02 d$ & $3.47 \pm 0.08 \mathrm{e}$ & $3.03 \pm 0.04 \mathrm{e}$ & $56.8 \pm 0.7 a$ & $19.4 \pm 0.5 b$ & $7.2 \pm 0.04 \mathrm{c}$ \\
\hline $\mathrm{TF}$ & $11.7 \pm 0.2 \mathrm{c}$ & $12.2 \pm 0.3 \mathrm{c}$ & $10.3 \pm 0.5 \mathrm{~d}$ & $18.12 \pm 0.04 b$ & $25.9 \pm 0.4 a$ & $6.9 \pm 0.1 \mathrm{e}$ \\
\hline TPC & $17.0 \pm 0.2 \mathrm{c}$ & $15.7 \pm 0.4 \mathrm{~d}$ & $13.3 \pm 0.4 \mathrm{e}$ & $74.9 \pm 0.7 a$ & $45.3 \pm 0.9 \mathrm{~b}$ & $14.1 \pm 0.07 \mathrm{e}$ \\
\hline
\end{tabular}

Calibration curves used to quantify the phenolic compounds: I - chlorogenic acid $\left(y=168823 x-161172, R^{2}=0.999\right)$; II $-p$-coumaric acid $(y=$ $\left.301950 x+6966.7 ; R^{2}=0.999\right) ;$ III - ferulic acid $\left(y=633126 x-185462 ; R^{2}=0.999\right) ;$ IV - apigenin-7-O-glucoside $\left(y=10683 x+45794 ; R^{2}=0.991\right)$. In each column different letters mean significant differences between samples $(p<0.05)$. nd: not detected; tr: traces; TPA: total phenolic acids; TF: total flavonoids; TPC: total phenolic compounds. ${ }^{a}$ For peak names consult Table 1.

Table 3 Retention time $\left(R_{\mathrm{t}}\right)$, wavelengths of maximum absorption in the visible region $\left(\lambda_{\text {max }}\right)$, mass spectral data and tentative identification of phenolic compounds in globe artichoke leaf midribs and petioles

\begin{tabular}{|c|c|c|c|c|c|}
\hline Peak & $\begin{array}{l}R_{\mathrm{t}} \\
(\mathrm{min})\end{array}$ & $\begin{array}{l}\lambda_{\max } \\
(\mathrm{nm})\end{array}$ & $\begin{array}{l}\text { Molecular ion } \\
{[\mathbf{M}-\mathbf{H}]^{-}(\mathrm{m} / \mathrm{z})}\end{array}$ & Main MS $^{2}$ fragments $(m / z)$ & Tentative identification \\
\hline 1 & 4.59 & 328 & 353 & 191(100), 179(40), 173(3), 161(10), 135(8) & cis 3-O-Caffeoylquinic acid \\
\hline 2 & 4.86 & 328 & 353 & 191(100), 179(46), 173(3), 161(8), 135(6) & trans 3 -O-Caffeoylquinic acid \\
\hline 4 & 11.3 & 328 & 515 & $353(82), 335(41), 191(41), 179(56), 173(95), 161(16), 135(26)$ & 1,3-O-Dicaffeoylquinic acid (cynarin) \\
\hline 5 & 16.5 & 280 & 463 & $287(100)$ & Eriodictyol-O-glucuronide \\
\hline 6 & 18.39 & 343 & 593 & $285(100)$ & Luteolin-7-O-rutinoside \\
\hline 9 & 20.36 & 327 & 515 & 353(94), 335(3), 191(100), 179(90), 173(10), 161(6), 135(40) & cis 3,5-O-Dicaffeoylquinic acid \\
\hline 10 & 21.02 & 327 & 515 & $353(94), 335(3), 191(100), 179(90), 173(10), 161(6), 135(40)$ & trans 3,5-O-Dicaffeoylquinic acid \\
\hline 11 & 22.50 & 327 & 515 & $353(94), 335(3), 191(100), 179(90), 173(10), 161(6), 135(40)$ & 4,5-O-Dicaffeoylquinic acid \\
\hline 12 & 23.27 & 329 & 615 & $515(100), 453(12), 353(56), 335(3), 191(3), 179(3)$ & Succinoyl-di-O-caffeoylquinic acid \\
\hline 13 & 24.27 & 347 & 533 & $489(100), 285(50)$ & Luteolin-7-O-malonylglucoside \\
\hline
\end{tabular}

Clifford et al. ${ }^{28,29}$ To the best of our knowledge, compound with peak number 12 is reported for the first time in artichoke leaves and is tentatively identified as succinoyl-di-O-caffeoylquinic acid, taking into account the fragmentation pattern reported by Jaiswal and Kuhnert. ${ }^{38}$

In contrast with leaf blades where flavonoid content was higher than phenolic acids in most of the genotypes (except for genotype SLB4), in petioles and midribs phenolic acids were the most abundant phenolic group in all the genotypes (64-76\% of TPC), except for genotype SPM6 where flavonoids prevailed over the phenolic acids (65\% of TPC) (Table 4). According to Pandino et al., ${ }^{39}$ the higher caffeoylquinic acid content in petioles and midribs could be attributed to their important role in cell wall structure and consequently in the mechanical and structural support they provide in leaf tissues. Phenolic acid content ranged from 4.4 (genotype SPM6) to
$12.8 \mathrm{mg}$ per $\mathrm{g}$ of extract (genotype SPM4), while the most abundant phenolic compounds were 5-O-caffeoylquinic acid (genotype SPM4), luteolin-7-O-glucoside and luteolin-7-Omalonylglucoside (genotype SPM6), and trans 3,5-O-dicaffeoylquinic acid (genotypes SPM3 and 5).

Reports regarding the phenolic compound composition of leaves show contradictory results. In particular, similarly to our study, Pandino et al. ${ }^{36}$ have detected significantly higher flavonoid content than phenolic acids in the leaves of clones of two Sicilian artichoke varieties, whereas Pistón et al., ${ }^{11}$ Sihem et al., ${ }^{40}$ and Pereira et al. ${ }^{34}$ have reported a higher content of phenolic acids than flavonoids in leaf extracts and dietary supplements, respectively. However, even in the study by Pandino et al., ${ }^{36}$ significant variation between the studied clones was observed, a finding that is similar to the results of the present study. Moreover, in our study, the contribution of 
Table 4 Phenolic compound quantification in leaf petioles and midribs (mg per g of extract) of the studied globe artichoke genotypes

\begin{tabular}{|c|c|c|c|c|c|c|}
\hline \multirow[b]{2}{*}{ Peak } & \multicolumn{6}{|l|}{ Genotypes } \\
\hline & SPM1 & SPM2 & SPM3 & SPM4 & SPM5 & SPM6 \\
\hline $1^{\mathrm{I} a}$ & $0.262 \pm 0.008 d$ & $0.248 \pm 0.007 d$ & $0.57 \pm 0.02 b$ & $0.262 \pm 0.006 \mathrm{~d}$ & $0.622 \pm 0.001 \mathrm{a}$ & $0.288 \pm 0.002 c$ \\
\hline $2^{\mathrm{I}}$ & $0.50 \pm 0.01 \mathrm{~cd}$ & $0.546 \pm 0.003 b c$ & $0.47 \pm 0.02 \mathrm{~d}$ & $0.96 \pm 0.07 \mathrm{a}$ & $0.61 \pm 0.04 \mathrm{~b}$ & $0.440 \pm 0.008 \mathrm{~d}$ \\
\hline $3^{\mathrm{I}}$ & $5.53 \pm 0.11 d$ & $7.54 \pm 0.16 b$ & $4.21 \pm 0.04 \mathrm{e}$ & $9.06 \pm 0.04 a$ & $6.14 \pm 0.03 c$ & $1.04 \pm 0.05 f$ \\
\hline $4^{\mathrm{I}}$ & $0.30 \pm 0.01 b$ & $0.291 \pm 0.004 b$ & $0.48 \pm 0.19 a$ & $0.268 \pm 0.009 b$ & $0.45 \pm 0.01 \mathrm{a}$ & $0.360 \pm 0.001 \mathrm{ab}$ \\
\hline $5^{\mathrm{I}}$ & $0.280 \pm 0.005 \mathrm{~d}$ & $0.287 \pm 0.002 c$ & $0.364 \pm 0.001 \mathrm{a}$ & $0.237 \pm 0.001 f$ & $0.266 \pm 0.00 \mathrm{e}$ & $0.294 \pm 0.003 b$ \\
\hline $8^{\mathrm{I}}$ & $1.10 \pm 0.01 \mathrm{~d}$ & $1.208 \pm 0.002 \mathrm{~d}$ & $2.57 \pm 0.03 b$ & $1.24 \pm 0.03 \mathrm{~cd}$ & $1.51 \pm 0.07 \mathrm{c}$ & $4.09 \pm 0.37 \mathrm{a}$ \\
\hline $9^{\mathrm{III}}$ & $0.297 \pm 0.002 c$ & $0.30 \pm 0.04 c$ & $0.64 \pm 0.06 b$ & $0.283 \pm 0.007 c$ & $0.646 \pm 0.002 b$ & $0.75 \pm 0.10 \mathrm{a}$ \\
\hline $10^{\mathrm{I}}$ & $2.73 \pm 0.09 b$ & $1.33 \pm 0.04 c$ & $3.36 \pm 0.16 a$ & $1.23 \pm 0.03 c$ & $3.57 \pm 0.19 a$ & $0.68 \pm 0.03 d$ \\
\hline $11^{\mathrm{I}}$ & $0.314 \pm 0.005 c$ & $0.28 \pm 0.01 d$ & $0.475 \pm 0.005 \mathrm{a}$ & $0.262 \pm 0.001 \mathrm{e}$ & $0.442 \pm 0.001 b$ & nd \\
\hline $12^{\mathrm{I}}$ & $0.24 \pm 0.01 \mathrm{c}$ & $0.245 \pm 0.001 c$ & $0.76 \pm 0.07 a$ & $0.245 \pm 0.004 c$ & $0.311 \pm 0.009 c$ & $0.41 \pm 0.08 b$ \\
\hline $13^{\mathrm{I}}$ & $1.02 \pm 0.01 \mathrm{~d}$ & $1.12 \pm 0.04 \mathrm{~d}$ & $1.82 \pm 0.03 b$ & $1.14 \pm 0.01 \mathrm{~d}$ & $1.52 \pm 0.01 \mathrm{c}$ & $2.85 \pm 0.21 \mathrm{a}$ \\
\hline
\end{tabular}

Calibration curves used to quantify the phenolic compounds: I - chlorogenic acid $\left(y=168823 x-161172, R^{2}=0.999\right)$; II - taxifolina $(y=$ $\left.203766 x-208383 ; R^{2}=0.999\right)$; III - apigenin-7-O-glucoside $\left(y=10683 x+45794 ; R^{2}=0.991\right)$. In each row different letters mean significant differences between samples $(p<0.05)$. nd: not detected; tr: traces; TPA: total phenolic acids; TF: total flavonoids; TPC: total phenolic compounds. ${ }^{a}$ For peak names consult Table 3.

TPA and TF in the TPC of whole leaves was balanced in all the genotypes, except for genotype SPM4 where $76 \%$ of TPC was attributed to TPA.

Considering that petioles and midribs constitute a larger portion of total leaf biomass compared to leaf blades, sample preparation could affect the phenolic compound composition of leaf extracts, since in homogenized samples the largest part will come from petioles and midribs. Therefore, the selection of specific leaf parts and genotypes could be a useful means for the reshaping of phenolic composition of leaf artichoke extracts, herbal preparations and dietary supplements.
Antioxidant activity differed significantly between the studied genotypes and the various assays (Table 5). Regarding leaf blades, genotype SLB4 showed the highest antioxidant activity in DPPH and reducing power (RP) assays, while it did not differ significantly with genotype SLB5 in TBARS. Considering the highest content of TPA and TPC in genotype SLB4 compared to the other genotypes, antioxidant activity of leaf blades, as indicated by the results of DPPH, RP and TBARS assays, could be attributed to total phenolic compound content. The same applies for the antioxidant activity of petioles and midribs, where genotypes SPM3 and SPM5 had

Table 5 Antioxidant properties of the studied globe artichoke genotypes

\begin{tabular}{|c|c|c|c|c|}
\hline Blades & $\mathrm{DPPH}\left(\mathrm{EC}_{50}\right.$ value, $\left.\mu \mathrm{g} \mathrm{mL}^{-1}\right)$ & $\mathrm{RP}\left(\mathrm{EC}_{50}\right.$ value, $\left.\mu \mathrm{g} \mathrm{mL}^{-1}\right)$ & $\beta$-Carotene $\left(\mathrm{EC}_{50}\right.$ value, $\left.\mu \mathrm{g} \mathrm{mL} \mathrm{m}^{-1}\right)$ & TBARS $\left(\mathrm{EC}_{50}\right.$ value, $\left.\mu \mathrm{g} \mathrm{mL}^{-1}\right)$ \\
\hline SLB1 & $1364 \pm 44 a$ & $682 \pm 4 c$ & $664 \pm 29 c$ & $1575 \pm 61 \mathrm{a}$ \\
\hline SLB2 & $850 \pm 13 d$ & $1039 \pm 9 b$ & $398 \pm 17 \mathrm{e}$ & $1047 \pm 37 b$ \\
\hline SLB3 & $913 \pm 41 c$ & $1111 \pm 2 a$ & $428 \pm 21 e$ & $801 \pm 23 c$ \\
\hline SLB4 & $369 \pm 9 f$ & $208.7 \pm 0.5 e$ & $515 \pm 27 d$ & $532 \pm 25 \mathrm{de}$ \\
\hline SLB5 & $537 \pm 9 e$ & $292 \pm 3 d$ & $1449 \pm 30 a$ & $502 \pm 16 \mathrm{e}$ \\
\hline SLB6 & $967 \pm 38 b$ & $685 \pm 8 c$ & $743 \pm 37 b$ & $555 \pm 27 d$ \\
\hline
\end{tabular}

\begin{tabular}{|c|c|c|c|c|}
\hline Petioles + midribs & $\mathrm{DPPH}\left(\mathrm{EC}_{50}\right.$ value, $\left.\mu \mathrm{g} \mathrm{mL}^{-1}\right)$ & $\mathrm{RP}\left(\mathrm{EC}_{50}\right.$ value, $\left.\mu \mathrm{g} \mathrm{mL} \mathrm{m}^{-1}\right)$ & $\beta$-Carotene $\left(\mathrm{EC}_{50}\right.$ value, $\left.\mu \mathrm{g} \mathrm{mL}^{-1}\right)$ & TBARS $\left(\mathrm{EC}_{50}\right.$ value, $\left.\mu \mathrm{g} \mathrm{mL}^{-1}\right)$ \\
\hline SPM1 & $2706 \pm 112 b$ & $1200 \pm 30 c$ & $4172 \pm 163 b$ & $1791 \pm 76 d$ \\
\hline SPM2 & $3786 \pm 77 a$ & $1275 \pm 9 b$ & $4013 \pm 69 c$ & $3837 \pm 22 \mathrm{a}$ \\
\hline SPM3 & $1367 \pm 64 \mathrm{e}$ & $889 \pm 12 f$ & $3048 \pm 85 e$ & $1215 \pm 37 e$ \\
\hline SPM4 & $2416 \pm 84 c$ & $1079 \pm 5 d$ & $6171 \pm 93 a$ & $2634 \pm 92 b$ \\
\hline SPM5 & $1952 \pm 33 d$ & $943 \pm 25 \mathrm{e}$ & $3401 \pm 154 d$ & $599 \pm 23 f$ \\
\hline SPM6 & $2329 \pm 82 c$ & $1785 \pm 5 a$ & $1588 \pm 17 f$ & $2030 \pm 99 c$ \\
\hline
\end{tabular}

The antioxidant activity was expressed as $\mathrm{EC}_{50}$ values, which means that higher values correspond to lower reducing power or antioxidant potential. $\mathrm{EC}_{50}$ : extract concentration corresponding to $50 \%$ antioxidant activity or 0.5 absorbance in the reducing power assay. Trolox $\mathrm{EC}_{50}$ values: $41 \mu \mathrm{g} \mathrm{mL} \mathrm{L}^{-1}$ (reducing power), $42 \mu \mathrm{g} \mathrm{mL} \mathrm{L}^{-1}$ (DPPH scavenging activity), $18 \mu \mathrm{g} \mathrm{mL} \mathrm{m}^{-1}$ ( $\beta$-carotene bleaching inhibition) and $23 \mu \mathrm{g} \mathrm{mL}{ }^{-1}$ (TBARS inhibition). In each column, different letters mean significant differences between samples $(p<0.05)$. 
the highest TPC content, which resulted in better antioxidant properties for the DPPH and RP (genotype SPM3) and TBARS (genotype SPM5) assays. However, the great differences in antioxidant activity between leaf blades, and petioles and midribs for all the assays do not conform to the differences in TPC between the leaf parts. Therefore, although phenolic compounds contribute to antioxidant properties, they cannot be considered as the only bioactive compounds responsible for such properties. Similar results have been reported by Sihem et al. ${ }^{40}$ who also suggested that the free scavenging activity of artichoke leaf tissues is not exclusively due to phenolic compound content. Moreover, in the same study, leaf extracts showed higher antioxidant activity in the reducing power assay compared to other tested assays (ABTS, DPPH and phosphomolybdenum assay), which is also the case in our study for the petioles and midribs of most of the genotypes.

In contrast, Pagano et al. ${ }^{32}$ have reported that the cellular antioxidant activity (CAA) of artichoke by-products (leaves and bracts) was significantly correlated with dicaffeoylquinic acids and total phenolics content. However, according to Kollia et al. ${ }^{8}$ the extraction method also has a significant impact on the antioxidant properties of artichoke leaf extracts, while the contribution of total phenolics content to antioxidant properties depends on the tested assay. Similar findings have been reported by Coinu et al., ${ }^{7}$ Pistón et al., ${ }^{11}$ and Vamanu et al. ${ }^{41}$ who suggested that antioxidant potency depends on the extraction method and solvents and is not related to total phenolics or individual phenolic subclass content.

\section{Conclusions}

In conclusion, significant variation in phenolic compound composition and total phenolic contents, as well as in antioxidant activities, was observed not only between the genotypes, but also, most importantly, between the leaf parts. The most abundant phenolics in leaf blades were 5-O-caffeoylquinic acid, luteolin-7-O-rutinoside, luteolin-7-O-glucoside, pinoresinol-4-O-hexoside, 3,5-O-dicaffeoylquinic acid and luteolin-7$O$-malonylglucoside, while in leaf petioles and midribs prevailed 5-O-caffeoylquinic acid, luteolin-7-O-glucoside, luteolin7-O-malonylglucoside and trans 3,5-O-dicaffeoylquinic acid. Genotype S4 has the highest phenolic compound content in the leaf blades (74.9 $\mathrm{mg}$ per $\mathrm{g}$ of extract), mostly due to the abundance of 5-O-caffeoylquinic acid, followed by genotype S5 (45.3 $\mathrm{mg}$ per $\mathrm{g}$ of extract) with similar amounts of flavonoids and phenolic acids being detected in its blades. The fact that in most of the studied genotypes, flavonoids prevailed in the leaf blades and phenolic acids in the petioles and midribs could be of major importance for the food and nutraceutical industries towards the design of new products, especially food additives that could increase the health benefits of various food products. Moreover, the great variation between the studied genotypes in terms of bioactive compounds highlights the importance of genetic conservation for breeding and therapeutic purposes.

\section{Author contributions}

S. Petropoulos and I. C. F. R. Ferreira conceived the study. C. Perreira and L. Barros carried out the experiments. L. Barros and I. C. F. R. Ferreira performed data organization and analysis of the results. S. Petropoulos and L. Barros wrote the manuscript. I. C. F. R. Ferreira revised the manuscript.

\section{Conflict of interest}

The authors declare that there are no conflicts of interest.

\section{Acknowledgements}

The authors acknowledge the Foundation for Science and Technology (FCT, Lisbon, Portugal) and the FEDER under Program PT2020 for financial support to CIMO (Pest-OE/AGR/ UI0690/2015) and L. Barros (SFRH/BPD/107855/2015) grants. Thanks are due to POCI-01-0145-FEDER-006984 (LA LSRE-LCM), funded by the FEDER, through POCI-COMPETE2020 and FCT.

\section{References}

1 J. Pérez-Jiménez, V. Neveu, F. Vos and A. Scalbert, Identification of the 100 richest dietary sources of polyphenols: an application of the Phenol-Explorer database, Eur. J. Clin. Nutr., 2010, 64(Suppl 3), S112-S120.

2 N. Ceccarelli, M. Curadi, P. Picciarelli, L. Martelloni, C. Sbrana and M. Giovannetti, Globe artichoke as a functional food, Med. J. Nutrition Metab., 2010, 3(3), 197-201.

3 V. Lattanzio, P. A. Kroon, V. Linsalata and A. Cardinali, Globe artichoke: A functional food and source of nutraceutical ingredients, J. Funct. Foods, 2009, 1(2), 131-144, DOI: 10.1016/j.jff.2009.01.002.

4 R. Llorach, J. C. Espín, F. A. Tomás-Barberán and F. Ferreres, Artichoke (Cynara scolymus L.) Byproducts as a potential source of health-promoting antioxidant phenolics, J. Agric. Food Chem., 2002, 50(12), 3458-3464.

5 C. Pereira, L. Barros, A. M. Carvalho, C. Santos-Buelga and I. C. F. R. Ferreira, Infusions of artichoke and milk thistle represent a good source of phenolic acids and flavonoids, Food Funct., 2015, 6(1), 56-62, DOI: 10.1039/c4fo00834k.

6 C. Pereira, R. C. Calhelha, L. Barros and I. C. F. R. Ferreira, Antioxidant properties, anti-hepatocellular carcinoma activity and hepatotoxicity of artichoke, milk thistle and borututu, Ind. Crops Prod., 2013, 49, 61-65, DOI: 10.1016/ j.indcrop.2013.04.032.

7 R. Coinu, S. Carta, P. P. Urgeghe, N. Mulinacci, P. Pinelli, F. Franconi, et al., Dose-effect study on the antioxidant properties of leaves and outer bracts of extracts obtained from Violetto di Toscana artichoke, Food Chem., 2007, 101(2), 524-531. 
8 E. Kollia, P. Markaki, P. Zoumpoulakis and C. Proestos, Antioxidant activity of Cynara scolymus L. and Cynara cardunculus L. extracts obtained by different extraction techniques, Nat. Prod. Res., 2016, 6419(August), 1-5, DOI: 10.1080/14786419.2016.1219864.

$9 \mathrm{X}$. Zhu, H. Zhang and R. Lo, Phenolic compounds from the leaf extract of artichoke (Cynara scolymus L.) and their antimicrobial activities, J. Agric. Food Chem., 2004, 52(24), 7272-7278.

10 H. Falleh, R. Ksouri, K. Chaieb, N. Karray-Bouraoui, N. Trabelsi, M. Boulaaba, et al., Phenolic composition of Cynara cardunculus L. organs, and their biological activities, C. R. Biol., 2008, 331(5), 372-379.

11 M. Pistón, I. Machado, C. S. Branco, V. Cesio, H. Heinzen, D. Ribeiro, et al., Infusion, decoction and hydroalcoholic extracts of leaves from artichoke (Cynara cardunculus L. subsp. cardunculus) are effective scavengers of physiologically relevant ROS and RNS, Food Res. Int., 2014, 64, 150-156, DOI: 10.1016/j.foodres.2014.05.078.

12 S. Lombardo, G. Pandino, G. Mauromicale, M. Knödler, R. Carle and A. Schieber, Influence of genotype, harvest time and plant part on polyphenolic composition of globe artichoke [Cynara cardunculus L. var. scolymus (L.) Fiori], Food Chem., 2010, 119(3), 1175-1181, DOI: 10.1016/ j.foodchem.2009.08.033.

13 G. Pandino, S. Lombardo, G. Mauromicale and G. Williamson, Profile of polyphenols and phenolic acids in bracts and receptacles of globe artichoke (Cynara cardunculus var. scolymus) germplasm, J. Food Compos. Anal., 2011, 24(2), 148-153, DOI: 10.1016/j.jfca.2010.04.010.

14 G. Pandino, S. Lombardo, A. Lo Monaco and G. Mauromicale, Choice of time of harvest influences the polyphenol profile of globe artichoke, J. Funct. Foods, 2013, 5(4), 1822-1828, DOI: 10.1016/j.jff.2013.09.001.

15 G. Pandino, S. Lombardo and G. Mauromicale, Mineral profile in globe artichoke as affected by genotype, head part and environment, J. Sci. Food Agric., 2011, 91(2), 302-308.

16 Y. Rouphael, M. Cardarelli, L. Lucini, E. Rea and G. Colla, Nutrient Solution Concentration Affects Growth, Mineral Composition, Phenolic Acids, and Flavonoids in Leaves of Artichoke and Cardoon, HortScience, 2012, 47(10), 14241429.

17 S. Lombardo, G. Pandino, A. Ierna and G. Mauromicale, Variation of polyphenols in a germplasm collection of globe artichoke, Food Res. Int., 2012, 46(2), 544-551, DOI: 10.1016/j.foodres.2011.06.047.

18 M. Lutz, C. Henríquez and M. Escobar, Chemical composition and antioxidant properties of mature and baby artichokes (Cynara scolymus L.), raw and cooked, J. Food Compos. Anal., 2011, 24(1), 49-54.

19 M. I. Alarcón-Flores, R. Romero-González, J. L. Martínez Vidal and A. Garrido Frenich, Determination of Phenolic Compounds in Artichoke, Garlic and Spinach by UltraHigh-Performance Liquid Chromatography Coupled to Tandem Mass Spectrometry, Food Anal. Methods, 2014, 7(10), 2095-2106.
20 M. Curadi, P. Picciarelli, R. Lorenzi, A. Graifenberg and N. Ceccarelli, Antioxidant activity and phenolic compounds in the edible parts of early and late italian artichoke (Cynara scolymus L.) varieties, Ital. J. Food Sci., 2005, 17(1), 33-44.

21 G. Pandino, F. L. Courts, S. Lombardo, G. Mauromicale and G. Williamson, Caffeoylquinic acids and flavonoids in the immature Inflorescence of globe artichoke, wild cardoon, and cultivated cardoon, J. Agric. Food Chem., 2010, 58(2), 1026-1031.

22 G. Pandino, S. Lombardo, R. P. Mauro and G. Mauromicale, Variation in polyphenol profile and head morphology among clones of globe artichoke selected from a landrace, Sci. Hortic., 2012, 138, 259-265, DOI: 10.1016/ j.scienta.2012.02.032.

23 A. Romani, P. Pinelli, C. Cantini, A. Cimato and D. Heimler, Characterization of Violetto di Toscana, a typical Italian variety of artichoke (Cynara scolymus L.), Food Chem., 2006, 95(2), 221-225.

24 B. de Falco, G. Incerti, M. Amato and V. Lanzotti, Artichoke: botanical, agronomical, phytochemical, and pharmacological overview, Phytochem. Rev., 2015, 14(6), 993-1018.

25 S. A. Petropoulos, C. Pereira, G. Ntatsi, N. Danalatos, L. Barros and I. C. F. R. Ferreira, Nutritional value and chemical composition of Greek artichoke genotypes, Food Chem., 2017, DOI: 10.1016/j.foodchem.2017.01.159.

26 S. M. F. Bessada, J. C. M. Barreira, L. Barros, I. C. F. R. Ferreira and M. B. P. P. Oliveira, Phenolic profile and antioxidant activity of Coleostephus myconis (L.) Rchb.f.: An underexploited and highly disseminated species, Ind. Crops Prod., 2016, 89, 45-51, DOI: 10.1016/ j.indcrop.2016.04.065.

27 S. A. Petropoulos, Â. Fernandes, L. Barros, I. C. F. R. Ferreira and G. Ntatsi, Morphological, nutritional and chemical description of "Vatikiotiko", an onion local landrace from Greece, Food Chem., 2015, 182, 156-163, DOI: S0308814615003519.

28 M. N. Clifford, J. Kirkpatrick, N. Kuhnert, H. Roozendaal and P. R. Salgado, LC-MS n analysis of the cis isomers of chlorogenic acids, Food Chem., 2008, 106(1), 379-385.

29 M. N. Clifford, K. L. Johnston, S. Knight and N. Kuhnert, Hierarchical scheme for LC-MSn identification of chlorogenic acids, J. Agric. Food Chem., 2003, 51(10), 29002911.

30 IUPAC, Nomenclature of cyclitols, Biochem. J., 1976, 153, 23-31.

31 Y. Rouphael, J. Bernardi, M. Cardarelli, L. Bernardo, D. Kane, G. Colla, et al., Phenolic Compounds and Sesquiterpene Lactones Profile in Leaves of Nineteen Artichoke Cultivars, J. Agric. Food Chem., 2016, 64(45), 8540-8548.

32 I. Pagano, A. L. Piccinelli, R. Celano, L. Campone, P. Gazzerro, E. Falco, et al., Chemical profile and cellular antioxidant activity of artichoke by-products, Food Funct., 2016, 7(12), 4841-4850. 
33 F. Sánchez-Rabaneda, O. Jáuregui, R. M. LamuelaRaventós, J. Bastida, F. Viladomat and C. Codina, Identification of phenolic compounds in artichoke waste by high-performance liquid chromatography-tandem mass spectrometry, J. Chromatogr., A, 2003, 1008(1), 57-72.

34 C. Pereira, L. Barros, M. Alves, C. Santos-Buelga and I. C. F. R. Ferreira, Artichoke and milk thistle pills and syrups as sources of phenolic compounds with antimicrobial activity, Food Funct., 2016, 7(7), 3083-3090.

35 S. C. Gouveia and P. C. Castilho, Phenolic composition and antioxidant capacity of cultivated artichoke, Madeira cardoon and artichoke-based dietary supplements, Food Res. Int., 2012, 48(2), 712-724, DOI: 10.1016/j.foodres.2012.05.029.

36 G. Pandino, S. Lombardo and G. Mauromicale, Globe artichoke leaves and floral stems as a source of bioactive compounds, Ind. Crops Prod., 2013, 44, 44-49, DOI: 10.1016/ j.indcrop.2012.10.022.

37 L. Barros, M. Dueñas, A. M. Carvalho, I. C. F. R. Ferreira and C. Santos-Buelga, Characterization of phenolic compounds in flowers of wild medicinal plants from Northeastern Portugal, Food Chem. Toxicol., 2012, 50(5), 1576-1582, DOI: 10.1016/j.fct.2012.02.004.

38 R. Jaiswal and N. Kuhnert, Identification and characterization of five new classes of chlorogenic acids in burdock (Arctium lappa L.) roots by liquid chromatography/tandem mass spectrometry, Food Funct., 2011, 2, 63-71.

39 G. Pandino, S. Lombardo, G. Mauromicale and G. Williamson, Phenolic acids and flavonoids in leaf and floral stem of cultivated and wild Cynara cardunculus L. genotypes, Food Chem., 2011, 126(2), 417-422, DOI: 10.1016/j.foodchem.2010.11.001.

40 D. Sihem, D. Samia, P. Gaetano, L. Sara, M. Giovanni, C. Hassiba, et al., In vitro antioxidant activities and phenolic content in crop residues of Tunisian globe artichoke, Sci. Hortic., 2015, 190, 128-136, DOI: 10.1016/ j.scienta.2015.04.014.

41 E. Vamanu, A. Vamanu, S. Nita and S. Colceriu, Antioxidant and Antimicrobial Activities of Ethanol Extracts of Cynara scolymus (Cynarae folium, Asteraceae Family), Trop. J. Pharm. Res., 2011, 10(6), 777-783. 